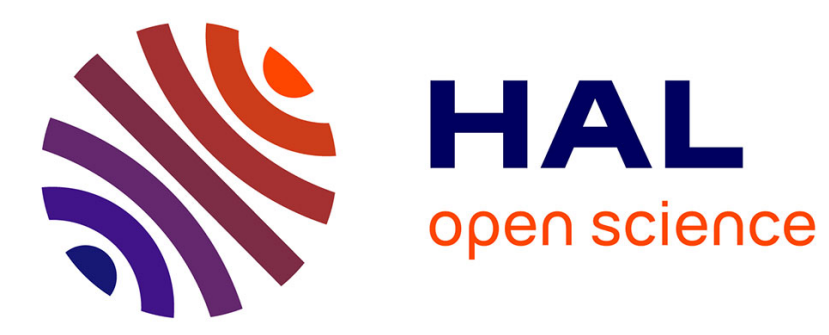

\title{
Ab initio calculations of structural and electronic properties of small silver bromide clusters
}

\author{
F. Rabilloud, F. Spiegelmann, J. Heully
}

\section{To cite this version:}

F. Rabilloud, F. Spiegelmann, J. Heully. Ab initio calculations of structural and electronic properties of small silver bromide clusters. Journal of Chemical Physics, 1999, 111 (19), pp.8925-8933. 10.1063/1.480237 . hal-03510633

\section{HAL Id: hal-03510633 \\ https://hal.science/hal-03510633}

Submitted on 13 Jan 2022

HAL is a multi-disciplinary open access archive for the deposit and dissemination of scientific research documents, whether they are published or not. The documents may come from teaching and research institutions in France or abroad, or from public or private research centers.
L'archive ouverte pluridisciplinaire HAL, est destinée au dépôt et à la diffusion de documents scientifiques de niveau recherche, publiés ou non, émanant des établissements d'enseignement et de recherche français ou étrangers, des laboratoires publics ou privés. 


\title{
$A b$ initio calculations of structural and electronic properties of small silver bromide clusters
}

\author{
F. Rabilloud \\ Laboratoire CAR (UMR 5589 CNRS-UPS), IRSAMC, Université Paul Sabatier, 118 Route de Narbonne, \\ F31062 Toulouse cedex 4, France \\ F. Spiegelmann and J. L. Heully \\ Laboratoire de physique quantique (UMR 5626 CNRS), IRSAMC, Université Paul Sabatier, \\ 118 Route de Narbonne, F31062 Toulouse cedex, France
}

(Received 4 June 1999; accepted 25 August 1999)

\begin{abstract}
Ab initio configuration interaction (CI) calculations are performed to study the ground state of small neutral and singly charged silver bromide clusters $\mathrm{Ag}_{n} \mathrm{Br}_{p}^{( \pm)}(n, p \leqslant 2)$. The results are obtained at complete active space self-consistent field and also at variational plus second order perturbational multireference CI (MRPT2) levels of approximation. We discuss more particulary the structural properties and the stability of the lowest isomers. Adiabatic and vertical ionization potentials and electron affinities have also been determined. (c) 1999 American Institute of Physics.
\end{abstract}

[S0021-9606(99)30843-6]

\section{INTRODUCTION}

After the study of homogeneous atomic clusters, mixed clusters have been the object of recent interest. Among them, metal halide and metal oxide systems have been particularly considered since they are good candidates to study the building of ionic or iono-covalent bonding in clusters. Stoichiometric alkali halides are known to be characterized by almost complete charge transfer and have been widely modelized via Coulomb plus polarization force fields added to BornMayer repulsive contributions. ${ }^{1-4}$ Non-stoichiometric clusters are also of appealing interest since they can be considered as prototype clusters to study insulator-to-metal transitions. By varying the stoichiometry $(n$ versus $p)$ in a cluster $M_{n} X_{p}$, one can change from purely ionic $(p=n)$ to metallic $(p=0)$ situation and examine changes in structural and electronic properties. ${ }^{5,6}$ Pseudopotentiel models for dealing with excess electrons have been successfully developped. ${ }^{7-10}$ Other metal halide clusters are of significant interest, such as halides of noble metals, which are however more tedious to study theoretically because of the possible role of $d$ electrons. Silver bromide has been highly used in imaging sciences for its known optical properties. Experimentally, the understanding of the elemental processes at the molecular scale has been undertaken in studying either the growth of small silver clusters in liquid phase ${ }^{11}$ or the adsorption of small silver clusters onto binder-free $\mathrm{AgBr}$ microcrystals. ${ }^{12}$

From the theoretical point of view, various works until now have investigated $\mathrm{AgBr}$ lattice properties ${ }^{13-15}$. A few studies were concerned with the calculation of properties concerning $\mathrm{Ag}_{n}$ clusters on $\mathrm{AgBr}$ surfaces ${ }^{16-18}$ and the interactions of halogen atoms with silver clusters. ${ }^{19}$ Almost no theoretical study is available to our knowledge on free moleculelike or small $\mathrm{Ag}_{n} \mathrm{Br}_{p}$ clusters.

In any case, electronic structure calculations are not easy due to the difficulty of correlating properly the $d$ shell of silver and the necessity to describe the relativistic effects. The influence of $d$ electrons on stability and spectroscopic patterns of homogeneous small silver clusters has already been discussed by Santamaria et al. in Ref. 20 and also by BonačićKoutecký et al. in Ref. 21. Studies concerned with silver oxides were also recently published by the latter authors ${ }^{22}$ and studies about magnesium and calcium oxides or alkali oxides were performed by Malliavin ${ }^{23}$ and Finocchi. ${ }^{24,25} \mathrm{We}$ present here an ab initio configuration interaction (CI) study of the ground state of small neutral and singly charged (positively and negatively) silver bromide clusters. The optimization of the geometrical structure is performed at two levels of approximation for the electronic structure, respectively, Complete Active Space Self-Consistent Field (CASSCF) and variational plus second-order perturbational multireference CI, hereafter labeled as MRPT2. We will discuss more particularly the structural properties, the stabilities of the low energy isomers and the character of the electronic wave functions with respect to charge transfer and localization in excess electron species. Moreover, the adiabatic and vertical ionization potentials and electron affinities are determined. The present work reports results for trimers and tetramers but in order to check the accuracy and reliability of the used calculation scheme, results on dimers are also given since partial experimental data and previous calculations are available. The interest is also to provide dimer dissociation energies with compatible accuracy for further calculations of fragmentation energetics on trimers and tetramers.

\section{METHOD}

Both $\mathrm{Ag}$ and $\mathrm{Br}$ atoms were represented through relativistic effective core pseudopotential (RECP). Silver was considered as an $\left[\mathrm{Ag}^{19+}\right]$ core with $4 s, 4 p, 4 d$, and $5 s$ active electrons ${ }^{26}$ whereas bromine was described with a $\left[\mathrm{Br}^{7+}\right]$ core and $4 s, 4 p$ active electrons. ${ }^{27}$ Calculations were achieved in the linear combination of atomic orbitals (LCAO) scheme. The gaussian type basis set was $8 s 7 p 6 d 1 f$ 
TABLE I. Gaussian atomic basis set for $\mathrm{Ag}$ and $\mathrm{Br}$.

\begin{tabular}{|c|c|c|c|c|}
\hline Atom & $\begin{array}{c}\text { Orbital } \\
\text { symmetry }\end{array}$ & No. & Exponent & $\begin{array}{c}\text { Contraction } \\
\text { coefficient }\end{array}$ \\
\hline \multirow[t]{22}{*}{$\mathrm{Ag}$} & \multirow[t]{8}{*}{$s$} & \multirow[t]{3}{*}{1} & 9.088442 & -1.964813 \\
\hline & & & 7.540731 & 2.733219 \\
\hline & & & 2.794005 & 0.199115 \\
\hline & & 2 & 1.480158 & 1.0 \\
\hline & & 3 & 0.653851 & 1.0 \\
\hline & & 4 & 0.124488 & 1.0 \\
\hline & & 5 & 0.049264 & 1.0 \\
\hline & & 6 & 0.016 & 1.0 \\
\hline & \multirow{7}{*}{$p$} & \multirow[t]{2}{*}{1} & 4.451240 & -6.083378 \\
\hline & & & 3.675263 & 6.416854 \\
\hline & & \multirow[t]{2}{*}{2} & 1.291288 & 0.753974 \\
\hline & & & 0.652578 & 0.273060 \\
\hline & & 3 & 0.367036 & 1.0 \\
\hline & & 4 & 0.075694 & 1.0 \\
\hline & & 5 & 0.023723 & 1.0 \\
\hline & \multirow[t]{6}{*}{$d$} & \multirow[t]{4}{*}{1} & 7.994730 & -0.016388 \\
\hline & & & 2.784773 & 0.281411 \\
\hline & & & 1.209744 & 0.486326 \\
\hline & & & 0.505393 & 0.386726 \\
\hline & & 2 & 0.198851 & 1.0 \\
\hline & & 3 & 0.066 & 1.0 \\
\hline & $f$ & 1 & 1.13 & 1.0 \\
\hline \multirow[t]{13}{*}{$\mathrm{Br}$} & \multirow[t]{6}{*}{$s$} & \multirow[t]{3}{*}{1} & 4.721881 & 0.10820 \\
\hline & & & 2.257555 & -0.4373 \\
\hline & & & 0.75 & -0.0088 \\
\hline & & 2 & 0.42 & 1.0 \\
\hline & & 3 & 0.2 & 1.0 \\
\hline & & 4 & 0.1 & 1.0 \\
\hline & \multirow[t]{6}{*}{$p$} & \multirow[t]{3}{*}{1} & 8.01 & 0.00270 \\
\hline & & & 1.896942 & -0.1798 \\
\hline & & & 0.910899 & 0.2431 \\
\hline & & 2 & 0.36 & 1.0 \\
\hline & & 3 & 0.15 & 1.0 \\
\hline & & 4 & 0.055 & 1.0 \\
\hline & $d$ & 1 & 0.389 & 1.0 \\
\hline
\end{tabular}

contracted into $6 s 5 p 3 d 1 f$ on silver and $6 s 6 p 1 d$ contracted into $4 s 4 p 1 d$ on bromine (Table I). The atomic basis set for Ag was that of Andrae et al. ${ }^{26}$ in which coefficients of the $p$ orbitals were uncontracted, and one $f$-symmetry function taken from ${ }^{28}$ was added to account for correlation of the $4 d$ shell. Moreover, two others $f$ functions (optimized exponents of 3.8 and 0.55 ) and one $g$ function (optimized exponent of 1.6) were tested on dimers but they occured to yield very small improvement and they were discarded.

In a first calculation, a gradient-driven optimization of geometry was performed at the CASSCF method with the MOLCAS4 package. ${ }^{29}$ The complete active space included all molecular orbitals built from $4 d, 5 s, 5 p$ on silver and $4 p$ on bromine. The $4 s, 4 p$ orbitals of silver and the $4 s$ orbital of bromine were kept inactive in the CAS but were allowed to relax in the SCF process. It was checked on trimers that inclusion of $4 d$ orbitals in the CAS was not essential in the structural optimization and they were kept inactive on tetramers. As an indication, the dimensions of the CASSCF spaces were 7312 and 6968 configurations for $\mathrm{Ag}_{2} \mathrm{Br}$ and $\mathrm{AgBr}_{2}$, respectively, in $C_{2 \mathrm{v}}$ symmetry group. In the case of tetramers, this dimension increases very quickly, up to more than $5 \times 10^{5}$ in $D_{2 h}$ symmetry and $10^{6}$ in $C_{2 v}$ symmetry even without including the $d$ orbitals in the active space.

Geometry optimization was further performed with a variational and second-order perturbational multireference CI calculation: following the above-mentioned CASSCF calculation, electronic correlation was introduced at a higher level with the three-class multireference perturbative CIPSI package. ${ }^{30}$ Namely, a variational calculation was achieved including the CAS subspace determinants built with molecular orbitals generated from the $5 s$ functions of silver and $4 p$ functions of bromine (class 1), augmented by all single excitations from the $4 d$ shell of silver towards these active orbitals and the single and double excitations from active orbitals to the virtual molecular orbitals built from $5 p$ functions of silver (class 2). CI in the so-defined multireference subspace generated a zeroth order wave function, the energy of which was perturbed up to second order of perturbation theory (MRPT2) using a Barycentric Møller-Plesset zeroth order Hamiltonian. ${ }^{31}$ All single and double excitations from that multireference CAS subspace were generated in the perturbation (class 3 ).

The calculations for trimers were carried out in the $C_{2 v}$ symmetry group at all levels of energy calculation and those for tetramers involved $C_{2 v}$ constraint at the CASSCF level and $D_{2 h}$ at the MRPT2 level of approximation. For each symmetry point group, CASSCF calculations (involving geometry optimization) were performed for electronic states belonging to various irreducible representations in order to check the symmetry of the ground state. Møller-Plesset (MP2) and local density (LDA) calculations were simultaneously achieved without symmetry constraint $\left(C_{1}\right)$ which confirmed the symmetry of the structures investigated in the present work.

In most cases, the equilibrium shapes obtained with the CASSCF and the MRPT2 scheme were found similar, except for the $\mathrm{Ag}_{2} \mathrm{Br}_{2}^{+}$and $\mathrm{Ag}_{2} \mathrm{Br}_{2}^{-}$tetramers. (See discussion in Sec. IV.)

In all calculations, spin-orbit coupling was neglected. It is not expected to play a crucial role at equilibrium for the ground state of clusters except in the case of dimers where a shift is expected for the dissociation energy, essentially due to the fine structure splitting on $\mathrm{Br}$ and $\mathrm{Br}^{+}$atoms. Our large basis for the silver atom, with some $s, p$, and $d$ diffuse functions, was tested on its electron affinity: we found $0.72 \mathrm{eV}$ in the CASSCF calculation and $1.37 \mathrm{eV}$ in the MRPT2 MøllerPlesset calculation, to be compared with the experimental value of $1.302 \mathrm{eV} .{ }^{32}$ Therefore, this basis set can describe both the neutral and negatively charged species. The values of the ionization potential are 6.37 and $7.16 \mathrm{eV}$ in the CASSCF and MRPT2 calculations respectively, to be compared with the experimental value of $7.57 \mathrm{eV}^{33}$

The electron affinity of $\mathrm{Br}$ was found to be $2.53 \mathrm{eV}$ in the CASSCF calculation and $3.02 \mathrm{eV}$ in the MRPT2 calculation. The last value is in decent agreement with the experimental data of $3.36 \mathrm{eV}^{34}$ The ionization potential was found to be $10.72 \mathrm{eV}$ and $11.19 \mathrm{eV}$ in the CASSCF and MRPT2 calculations respectively, to be compared with the experimental value of $11.81 \mathrm{eV}{ }^{35}$ 
TABLE II. Spectroscopic constants $\left(r_{e}, D_{e}, \omega_{e}\right)$ for the neutral and singly charged (positively and negatively) dimers.

\begin{tabular}{|c|c|c|c|c|}
\hline Species & Method/Ref. & $r_{e}\left(a_{0}\right)$ & $D_{e}(\mathrm{eV})$ & $\omega_{e}\left(\mathrm{~cm}^{-1}\right)$ \\
\hline \multirow{10}{*}{$\operatorname{Ag}_{2}\left({ }^{1} \Sigma_{g}^{+}\right)$} & CASSCF this work & 5.16 & 1.11 & \\
\hline & MRPT2 this work & 4.78 & 1.96 & 199.9 \\
\hline & CI(SD) Ref. 38 & 4.90 & 1.00 & 176 \\
\hline & $\mathrm{CI}(\mathrm{SD})+\mathrm{Q}$ Ref. 38 & 4.87 & 1.20 & 180 \\
\hline & CEPA1 Ref. 38 & 4.88 & 1.36 & 176 \\
\hline & LMRCI Ref. 28 & 4.88 & 1.43 & 198 \\
\hline & MP4(SDQ) Ref. 41 & 4.82 & 1.48 & 179 \\
\hline & CPF Ref. 42 & 4.89 & 1.48 & 178 \\
\hline & MCPF Ref. 39 & 5.02 & 1.34 & 162 \\
\hline & Expt. & $4.78^{\mathrm{a}}$ & $1.66^{\mathrm{b}}$ & $192.4^{\mathrm{e}}$ \\
\hline \multirow[t]{7}{*}{$\mathrm{Ag}_{2}^{-}\left({ }^{2} \Sigma_{u}^{+}\right)$} & CASSCF this work & 5.52 & 1.09 & \\
\hline & MRPT2 this work & 5.00 & 1.43 & 153.7 \\
\hline & CI(SD) Ref. 38 & 5.18 & 0.93 & 123 \\
\hline & $\mathrm{CI}(\mathrm{SD})+\mathrm{Q}$ Ref. 38 & 5.14 & 1.06 & 128 \\
\hline & CEPA1 Ref. 38 & 5.14 & 1.16 & 127 \\
\hline & MCPF Ref. 39 & 5.32 & 1.12 & 118 \\
\hline & Expt. & & $1.39^{\mathrm{c}}$ & \\
\hline \multirow{6}{*}{$\mathrm{Ag}_{2}^{+}\left({ }^{2} \Sigma_{g}^{+}\right)$} & CASSCF this work & 5.70 & 1.24 & \\
\hline & MRPT2 this work & 5.15 & 1.69 & 135.3 \\
\hline & CI(SD) Ref. 38 & 5.36 & 1.33 & 108 \\
\hline & CI(SD)+Q Ref. 38 & 5.30 & 1.39 & 114 \\
\hline & CEPA1 Ref. 38 & 5.27 & 1.41 & 116 \\
\hline & Expt. & & $1.66^{\mathrm{d}}$ & \\
\hline \multirow{6}{*}{$\mathrm{Br}_{2}\left({ }^{1} \Sigma_{g}^{+}\right)$} & CASSCF this work & 4.45 & 1.36 & \\
\hline & MRPT2 this work & 4.42 & 2.01 & 300.9 \\
\hline & MRD CI Ref. 44 & 4.39 & 2.31 & 309 \\
\hline & CASSCF/FOCI Ref. 45 & 4.42 & 1.88 & 319 \\
\hline & CASSCF/SOCI Ref. 45 & 4.40 & 1.87 & 321 \\
\hline & Expt. & $4.31^{\mathrm{e}}$ & $1.99^{\mathrm{e}}$ & $325.3^{\mathrm{e}}$ \\
\hline \multirow[t]{4}{*}{$\mathrm{Br}_{2}^{-}\left({ }^{2} \Sigma_{u}^{+}\right)$} & CASSCF this work & 5.46 & 1.19 & \\
\hline & MRPT2 this work & 5.42 & 1.10 & 155.0 \\
\hline & MRD CI Ref. 44 & 5. 31 & 1.34 & 178 \\
\hline & Expt. & & $1.15^{\mathrm{e}}$ & \\
\hline \multirow{4}{*}{$\mathrm{Br}_{2}^{+}\left({ }^{2} \Pi_{g}\right)$} & CASSCF this work & 4.26 & 2.70 & \\
\hline & MRPT2 this work & 4.25 & 2.61 & 342.5 \\
\hline & CASSCF/FOCI Ref. 45 & 4.35 & 2.7 & 343 \\
\hline & Expt. & & $3.28^{\mathrm{e}}$ & $376.0^{\mathrm{e}}$ \\
\hline \multirow[t]{3}{*}{$\operatorname{AgBr}\left({ }^{1} \Sigma^{+}\right)$} & CASSCF this work & 4.73 & 3.13 & \\
\hline & MRPT2 this work & 4.58 & 2.67 & 243.8 \\
\hline & Expt. & $4.52^{\mathrm{f}}$ & $3.1^{\mathrm{g}}$ & $247.7^{\mathrm{e}}$ \\
\hline \multirow[t]{2}{*}{$\mathrm{AgBr}^{-}\left({ }^{2} \Sigma^{+}\right)$} & CASSCF this work & 5.15 & 0.79 & \\
\hline & $\begin{array}{l}\text { MRPT2 this work } \\
\text { Expt. }\end{array}$ & 4.92 & 1.03 & 157.6 \\
\hline \multirow[t]{3}{*}{$\mathrm{AgBr}^{+}\left({ }^{2} \Pi\right)$} & CASSCF this work & 5.34 & 0.82 & \\
\hline & MRPT2 this work & 5.02 & 0.89 & 140.9 \\
\hline & Expt. & & $1.41^{\mathrm{h}}$ & \\
\hline
\end{tabular}

${ }^{\mathrm{a}}$ Reference 35.

${ }^{\mathrm{b}}$ Reference 43.

${ }^{\mathrm{c}}$ Reference 4 in Ref. 39.

${ }^{\mathrm{d}}$ Value of $D_{0}^{0}$ : Ref. 26 in Ref. 40.

eReference 36.

${ }^{\mathrm{f}}$ Reference 37.

${ }^{\mathrm{g}}$ Value of $D_{0}^{0}$ : Ref. 36.

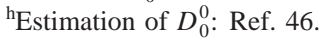

\section{RESULTS ON DIMERS}

Results on silver and bromine dimers, for which partial theorical and experimental data are available, allow us to check the accuracy of the present calculations. The calculated spectroscopic constants are shown in Table II at both CASSCF and MRPT2 levels of approximation.

The experimental dimer equilibrium distances are only
TABLE III. Adiabatic/vertical ionization potentials (in eV).

\begin{tabular}{lccr}
\hline \hline Species & CASSCF & $\begin{array}{c}\text { IP (eV) } \\
\text { MRPT2 }\end{array}$ & Expt. \\
\hline $\mathrm{Ag}_{2}$ & $6.29 / 6.38$ & $7.58 / 7.68$ & $7.56^{\mathrm{a}}$ \\
$\mathrm{Br}$ & $9.87 / 9.94$ & $10.20 / 10.25$ & $10.52^{\mathrm{b}}$ \\
$\mathrm{AgBr}$ & $8.39 / 8.57$ & $8.84 / 9.00$ & $9.26^{\mathrm{c}}$ \\
$\mathrm{Ag} 2 \mathrm{Br}$ & $4.75 / 5.58$ & $5.88 / 6.46$ & \\
$\mathrm{AgBr}_{2}$ & $6.78 / 7.87$ & $8.02 / 8.83$ & \\
$\mathrm{Ag}_{2} \mathrm{Br}_{2}$ & $7.67 / 9.49$ & $8.78 / 9.15$ & \\
\hline \hline
\end{tabular}

${ }^{\mathrm{a}}$ Reference 26 in Ref. 40.

${ }^{\mathrm{b}}$ Reference 47.

${ }^{c}$ Estimate value in Ref. 46.

known for $\mathrm{Ag}_{2}, \mathrm{Br}_{2}$, and $\mathrm{AgBr}$. The present CASSCF optimized distances (respectively, 5.16, 4.45, and $4.73 a_{0}$ ) are overestimated with respect to the experimental values (respectively $4.78 a_{0},{ }^{35} 4.31 a_{0},{ }^{36}$ and $4.52 a_{0}{ }^{37}$ ) which is probably due to the lack of electron correlation and may provide a scaling error for the geometries of larger clusters optimized at the same level of accuracy. The MRPT2 calculations provide a significant improvement, yielding values $\left(4.78,4.42\right.$, and $4.58 a_{0}$, respectively) in much closer agreement with the experimental data. One may remark that the CASSCF error is much larger on $\mathrm{Ag}_{2}$ than on $\mathrm{AgBr}$ or $\mathrm{Br}_{2}$. The MRPT2 optimized equilibrium distances for the charged dimers are 5.00, 5.15, 5.42, 4.25, 4.92, and $5.02 a_{0}$ for $\mathrm{Ag}_{2}^{-}$, $\mathrm{Ag}_{2}^{+}, \mathrm{Br}_{2}^{-}, \mathrm{Br}_{2}^{+}, \mathrm{AgBr}^{-}$, and $\mathrm{AgBr}^{+}$, respectively. The CASSCF values on bromide dimers are very close to the MRPT2 values. It appears that the $r_{e}$ values of ions are longer than those of neutral dimers except for $\mathrm{Br}_{2}^{+}\left(0.19 a_{0}\right.$ shorter than that of $\mathrm{Br}_{2}$ ). The CASSCF dissociation energies are generally underestimated with respect to experimental values. Again, the MRPT2 calculations are very close to the experimental data with however the exceptions of $\mathrm{Br}_{2}^{+}$, $\mathrm{AgBr}$, and $\mathrm{AgBr}^{+}$. The present dissociation energies for $\mathrm{Ag}_{2}^{+}$ and $\mathrm{Ag}_{2}^{-}$are of comparable or usually better accuracy than those of previous sophisticated calculations dealing explicitly with dimers ${ }^{38-40}$. In the case of $\mathrm{Ag}_{2}$ the perturbation contribution exaggerates the dissociation energy. When the CASSCF space is increased, the results improve. However, we have kept here the results obtained by a method consistent with those presented below on larger clusters. The values for $\mathrm{Br}_{2}, \mathrm{Br}_{2}^{+}$, and $\mathrm{Br}_{2}^{-}$are also in good agreement with previous theoretical determinations. ${ }^{44,45}$

In MRPT2 calculations, the spectroscopic constant $\omega_{e}$ are found to be in good agreement with the experimental data when available. The relative errors vary from $2 \%$ for $\mathrm{AgBr}$ to $9 \%$ for $\mathrm{Br}_{2}^{+}$. The $\omega_{e}$ value on silver dimers are slighty larger than those of previous calculations and slightly smaller on bromide dimers.

The adiabatic and vertical ionization potentials and electron affinities for the neutral dimers are shown in Tables III and IV. The CASSCF values are about $1 \mathrm{eV}$ smaller than those of the MRPT2 calculations. The MRPT2 adiabatic ionization potentials for the dimers $\mathrm{Ag}_{2}, \mathrm{Br}_{2}$, and $\mathrm{AgBr}$ (respectively, $7.58,10.20$, and $8.84 \mathrm{eV}$ ) agree within $5 \%$ with the experimental ionization potentials (respectively, 7.56, 10.52, and $9.26 \mathrm{eV}$ ). The calculated adiabatic electron affinities for 
TABLE IV. Adiabatic/vertical electron affinities (in eV).

\begin{tabular}{|c|c|c|c|}
\hline Species & CASSCF & $\begin{array}{l}\text { EA }(e V) \\
\text { MRPT2 }\end{array}$ & Expt. \\
\hline $\mathrm{Ag}_{2}$ & $0.48 / 0.44$ & $0.84 / 0.81$ & $1.02^{\mathrm{a}}$ \\
\hline $\mathrm{Br}_{2}$ & $1.75 / 0.72$ & $2.55 / 1.56$ & $2.55^{\mathrm{b}}$ \\
\hline $\mathrm{AgBr}$ & $0.59 / 0.48$ & $1.50 / 1.41$ & \\
\hline $\mathrm{Ag}_{2} \mathrm{Br}$ & $1.17 / 1.11$ & $1.77 / 1.63$ & \\
\hline $\mathrm{AgBr}_{2}$ & $4.44 / 1.77$ & $4.85 / 2.23$ & \\
\hline $\mathrm{Ag}_{2} \mathrm{Br}_{2}$ & $1.45 / 0.37$ & $0.79 / 0.78$ & \\
\hline
\end{tabular}

${ }^{a}$ Reference 48.

${ }^{\mathrm{b}}$ Reference 47

$\mathrm{Ag}_{2}, \mathrm{Br}_{2}$, and $\mathrm{AgBr}$ are $0.84,2.55$, and $1.50 \mathrm{eV}$, respectively, experimental data are only available for $\mathrm{Ag}_{2}$ and $\mathrm{Br}_{2}$ (respectively, 1.02 and $2.55 \mathrm{eV}$ ). The vertical electron affinities, which correspond to the geometries of the neutral species are close to the adiabatic values except for $\mathrm{Br}_{2}$ due to a $0.8 a_{0}$ equilibrium distance shift between $\mathrm{Br}_{2}$ and $\mathrm{Br}_{2}^{-}$.

\section{TRIMERS AND TETRAMERS}

Now, we will discuss the structural (Fig. 1) and electronic properties of stable trimers. We will be interested in the stability of the lowest isomers. A CASSCF electronic density study (density contour plot) enables us to discuss the ionic character of the bonding. A few but characteristic orbital density contour plots are shown below. The CASSCF optimized geometries will be compared to those of the MRPT2 calculations (Table V). The nature of the states and
TABLE V. CASSCF and MRPT2 optimized geometries and dissociation channels of trimers $X_{2} Y$ in the ground state. $d$ is the $X-Y$ bonding distance in $a_{0}, \alpha$ is the $\widehat{X Y X}$ angle in degrees.

\begin{tabular}{|c|c|c|c|c|}
\hline \multirow[b]{2}{*}{ Species } & \multicolumn{2}{|c|}{ CASSCF } & \multicolumn{2}{|c|}{ MRPT2 } \\
\hline & $d$ & $\alpha$ & $d$ & $\alpha$ \\
\hline $\mathrm{Ag}_{2} \mathrm{Br}$ & 5.2 & 64 & 5.0 & 61 \\
\hline $\mathrm{Ag}_{2} \mathrm{Br}^{-}$ & 5.5 & 63 & 5.6 & 53 \\
\hline $\mathrm{Ag}_{2} \mathrm{Br}^{+}$ & 5.0 & 127 & 4.8 & 111 \\
\hline $\mathrm{AgBr}_{2}$ & 5.1 & 66 & 5.1 & 67 \\
\hline $\mathrm{AgBr}_{2}^{-}$ & 4.9 & 180 & 4.7 & 180 \\
\hline $\mathrm{AgBr}_{2}^{+}$ & 5.8 & 45 & 5.6 & 47 \\
\hline
\end{tabular}

the energies of all systems studied are given in Table VI. The conformations of the lowest neutral and charged trimers show that isosceles triangular shapes $\left(C_{2 v}\right.$ symmetry group) were found in all cases except for $\mathrm{AgBr}_{2}^{-}$in which the equilibrium geometry is a $D_{\infty h}$ linear structure. The $D_{\infty h}$ linear structure is found as a saddle point for $\mathrm{AgBr}_{2}, \mathrm{Ag}_{2} \mathrm{Br}$, $\mathrm{Ag}_{2} \mathrm{Br}^{-}$, and $\mathrm{Ag}_{2} \mathrm{Br}^{+}$.

The shape of $\mathrm{Ag}_{2} \mathrm{Br}$ is an isosceles triangle with an angle $\widehat{A g B r A g}$ of 61 degrees. The electron density analysis can be compared with that of an alkali halide trimer $\mathrm{Na}_{2} \mathrm{~F}$ for which the $\mathrm{Na}-\mathrm{F}$ bondings are ionic and where the excess electron is localized at the apex of a rhombus, replacing the missing fluorine atom with respect to $\mathrm{Na}_{2} \mathrm{~F}_{2} \cdot{ }^{9}$ The $\mathrm{Na}_{2} \mathrm{~F}$ cluster can thus be described symbolically as $\mathrm{Na}^{+} \mathrm{F}^{-} \mathrm{Na}^{+}$plus one electron. In the $\mathrm{Ag}_{2} \mathrm{Br}$ trimer, the situation is slightly different in
$\mathrm{AgBr}$

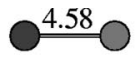

$\mathrm{Ag}_{2} \mathrm{Br}$

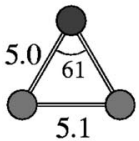

$\mathrm{Ag}_{2} \mathrm{Br}^{-}$

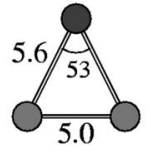

$\mathrm{AgBr}_{2}$

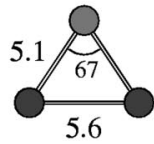

$\mathrm{AgBr}_{2}^{-}$

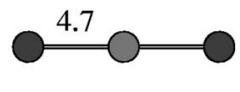

$\mathbf{A g B r}_{2}^{+}$

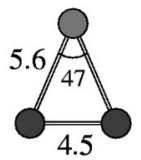

$\mathbf{A g}_{2} \mathbf{B r}_{2}^{+}$

$\mathrm{Ag}_{2} \mathrm{Br}^{+}$

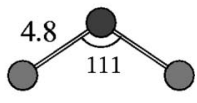

4.5

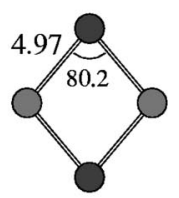

FIG. 1. Optimized geometrical structure of $\mathrm{Ag}_{n} \mathrm{Br}_{p}^{( \pm)}$clusters. Distances are in Bohr, angles in degrees.
$\mathbf{A g}_{2} \mathrm{Br}_{2}$

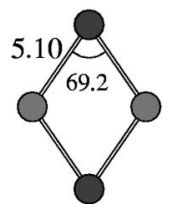

$\mathrm{Ag}_{2} \mathrm{Br}_{2}^{-}$

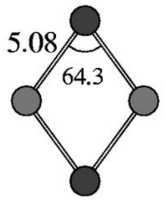


TABLE VI. MRPT2 energy of the ground state (in Hartree).

\begin{tabular}{|c|c|c|c|}
\hline Species & Symmetry & State & MRPT2 energy \\
\hline $\mathrm{Ag}$ & & ${ }^{2} S$ & -146.333042 \\
\hline $\mathrm{Ag}^{-}$ & & ${ }^{1} S$ & -146.383317 \\
\hline $\mathrm{Ag}^{+}$ & & ${ }^{1} S$ & -146.069875 \\
\hline $\mathrm{Br}$ & & ${ }^{2} P$ & -13.230192 \\
\hline $\mathrm{Br}^{-}$ & & ${ }^{1} S$ & -13.341128 \\
\hline $\mathrm{Br}^{+}$ & & ${ }^{3} P$ & -12.819098 \\
\hline $\mathrm{Ag}_{2}$ & & ${ }^{1} \Sigma_{g}^{+}$ & -292.742642 \\
\hline $\mathrm{Ag}_{2}^{-}$ & & ${ }^{2} \Sigma_{u}^{+}$ & -292.773604 \\
\hline $\mathrm{Ag}_{2}^{+}$ & & ${ }^{2} \Sigma_{g}^{+}$ & -292.463981 \\
\hline $\mathrm{Br}_{2}$ & & ${ }^{1} \Sigma_{g}^{g}$ & -26.522914 \\
\hline $\mathrm{Br}_{2}^{-}$ & & ${ }^{2} \Sigma_{u}^{+}$ & -26.616724 \\
\hline $\mathrm{Br}_{2}^{+}$ & & ${ }^{2} \Pi_{g}$ & -26.148242 \\
\hline $\mathrm{AgBr}$ & & ${ }^{1} \Sigma^{+}$ & -159.660534 \\
\hline $\mathrm{AgBr}^{-}$ & & ${ }^{2} \Sigma^{+}$ & -159.715777 \\
\hline $\mathrm{AgBr}^{+}$ & & ${ }^{2} \Pi$ & -159.335623 \\
\hline $\mathrm{Ag}_{2} \mathrm{Br}$ & $C_{2 \mathrm{v}}$ & ${ }^{2} A_{1}$ & -306.028115 \\
\hline $\mathrm{Ag}_{2} \mathrm{Br}^{-}$ & $C_{2 \mathrm{v}}$ & ${ }^{1} A_{1}$ & -306.092991 \\
\hline $\mathrm{Ag}_{2} \mathrm{Br}^{+}$ & $C_{2 \mathrm{v}}$ & ${ }^{1} A_{1}$ & -305.811939 \\
\hline $\mathrm{AgBr}_{2}$ & $C_{2 \mathrm{v}}$ & ${ }^{2} B_{2}$ & -172.926962 \\
\hline $\mathrm{AgBr}_{2}^{-}$ & $C_{2 \mathrm{v}}$ & ${ }^{1} A_{1}$ & -173.105200 \\
\hline $\mathrm{AgBr}_{2}^{+}$ & $C_{2 \mathrm{v}}$ & ${ }^{1} A_{1}$ & -172.632370 \\
\hline $\mathrm{Ag}_{2} \mathrm{Br}_{2}$ & $D_{2 h}$ & ${ }^{1} A_{g}$ & -319.394415 \\
\hline $\mathrm{Ag}_{2} \mathrm{Br}_{2}^{-}$ & $D_{2 h}$ & ${ }^{2} A_{g}^{8}$ & -319.423409 \\
\hline $\mathrm{Ag}_{2} \mathrm{Br}_{2}^{+}$ & $D_{2 h}$ & ${ }^{2} B_{2} u$ & -319.071660 \\
\hline
\end{tabular}

so far that the electron density is intermediate between the former case and an $\mathrm{Ag}_{2}^{+} \mathrm{Br}^{-}$configuration. The single electron is localized closer to the $\mathrm{Ag}-\mathrm{Ag}$ bond as shown in Fig. 2 where the HOMO (9) $a_{1}$ is plotted. This can be due to the scaling of the $\mathrm{AgBr}$ and $\mathrm{Ag}_{2}^{+} / \mathrm{Ag}_{2}$ distances resulting in an almost equilateral triangle, while in $\mathrm{Na}_{2} \mathrm{~F}$ the $\mathrm{Na}-\mathrm{Na}$ bond length is longer than that of $\mathrm{NaF}$ resulting in an obtuse $\mathrm{Na} \widehat{\mathrm{F}} \mathrm{Na}$ angle (105.7 degrees $\left.{ }^{9}\right)$ and a four-center charge electrostatic stabilization. The others molecular orbitals resemble very much those of isolated $\mathrm{Ag}^{+}$or $\mathrm{Br}^{-}$with perhaps a weak delocalization of the $p_{z}$ orbital (8) $a_{1}$ of bromine (Fig. 2).

Interestingly in $\mathrm{Ag}_{2} \mathrm{Br}^{+}$, the $\mathrm{Ag}^{+}-\mathrm{Ag}^{+}$repulsion is no longer screened by the excess electron, yielding an open triangle with an apex angle of 111 degrees. The electron density analysis shows that the structure is ionic, namely close to $\mathrm{Ag}^{+} \mathrm{Br}^{-} \mathrm{Ag}^{+}$. The orbital plots of the in-plane orbitals (8) $a_{1}$ and (7) $b_{2}$ (Fig. 3) show that some significant delocalization however subsists along the $\mathrm{AgBr}$ bonds in the latter orbital. The others electrons do not participate significantly in the (8)a1

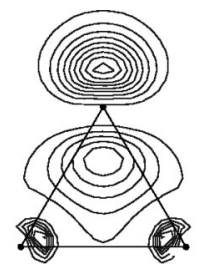

(9) a1

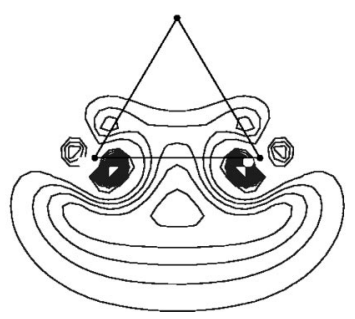

FIG. 2. Density contour plots of representative orbitals of $\mathrm{Ag}_{2} \mathrm{Br}$. (8)a1

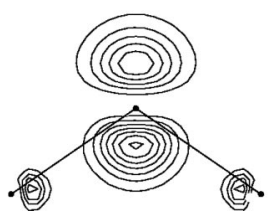

(7)b2

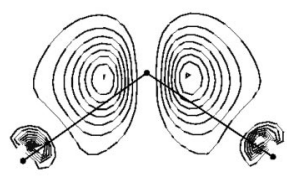

FIG. 3. Density contour plots of representative orbitals of $\mathrm{Ag}_{2} \mathrm{Br}^{+}$.

bonding, except for electrostatic contributions. The bond length between silver and bromine atoms is smaller than that in $\mathrm{AgBr}^{+}$(4.8 versus 5.02a $a_{0}$.

The CASSCF optimization of the negatively charged cluster $\mathrm{Ag}_{2} \mathrm{Br}^{-}$yields two isosceles triangles with a relative energy of $0.01 \mathrm{eV}$ belonging to the same electronic representation ${ }^{1} A_{1}$. The conformation of the lowest one is an acute isosceles triangle in which the $\mathrm{Ag} \widehat{\mathrm{Br}} \mathrm{Ag}$ angle is 63 degrees and the bonding distance between $\mathrm{Ag}$ and $\mathrm{Br}$ is $5.5 a_{0}$. The second one is an obtuse isosceles triangle with a $\mathrm{Ag} \widehat{\mathrm{BrAg}}$ angle of 110 degrees and an $\mathrm{Ag}-\mathrm{Br}$ distance of $5.3 a_{0}$. In the MRPT2 calculation, the obtuse isomer disappears while the apex angle of the remaining acute isomer is reduced by 10 degrees. The shape is close to that of $\mathrm{Ag}_{2} \mathrm{Br}$ with increased $\mathrm{AgBr}$ distances. The electronic charge density allows to analyze it as $\mathrm{Br}^{-} \mathrm{Ag}_{2}$. The two electrons in the (9) $a_{1}$ orbital (similar to that of $\mathrm{Ag}_{2} \mathrm{Br}$ ), essentially spanned by $\mathrm{Ag}_{2}$, yield a further screening and a correlative increase of the $\mathrm{AgBr}$ bond length.

The shape of $\mathrm{AgBr}_{2}$ is again an acute isosceles triangle. The electron density analysis reveals it as $\mathrm{Ag}^{+} \mathrm{Br}_{2}^{-}$. The occupied orbitals are close to those of $\mathrm{Br}_{2}^{-}$, slightly distorted. The transferred electron occupies molecular orbital $(5) b_{2}$ correlated with the $\sigma_{u}$ valence orbital of $\mathrm{Br}_{2}^{-}$. This is consistent with a $\mathrm{Br}-\mathrm{Br}$ distance of $5.6 a_{0}$ as compared with the equilibrium distance of $\mathrm{Br}_{2}^{-}\left(5.5 a_{0}\right)$.

$\mathrm{AgBr}_{2}^{+}$can be analyzed as $\mathrm{Ag}^{+} \mathrm{Br}_{2}$ with a $\mathrm{Br}-\mathrm{Br}$ distance close to that of the dimer $\mathrm{Br}_{2}$ and an apex angle of 47 degrees. This electronic configuration is not unexpected since the ionization potential of $\mathrm{Ag}$ is lower than that of $\mathrm{Br}_{2}$ (The MRPT2 values are $7.16 \mathrm{eV}$ and $10.20 \mathrm{eV}$, respectively.) A $D_{\infty h}$ linear isomer is also found with an $\mathrm{AgBr}$ bond of $4.8 a_{0}$, and a relative CASSCF energy of $0.73 \mathrm{eV}$ with respect to the ground state. This structure can be analyzed as $\mathrm{BrAg}^{+} \mathrm{Br}$.

Finally, the negative $\mathrm{AgBr}_{2}^{-}$trimer has a $D_{\infty h}$ linear geometry and corresponds to an electronic configuration $\mathrm{Br}^{-} \mathrm{Ag}^{+} \mathrm{Br}^{-}$and an almost complete localization of the electrons on bromine and a clear charge transfer. The $\mathrm{Ag}-\mathrm{Br}$ distance is close to that of the neutral dimer (4.7 versus $\left.4.6 a_{0}\right)$.

We now discuss the tetramer case. The rhombus is the most stable geometry of $\mathrm{Ag}_{2} \mathrm{Br}_{2}$, both at the CASSCF and at the MRPT2 optimization level. Comparing CASSCF versus MRPT2 calculations, the $\mathrm{AgBr}$ distances remain about the same $\left(5.1 a_{0}\right)$, while the $\mathrm{Ag} \widehat{\mathrm{Br} A g}$ is reduced from 72.7 to 69.2 degrees. From the orbital density plots of Fig. 4, it appears that the cluster can be considered as essentially ionic. The main deviations from this situation should appear for the in-plane orbitals without nodal perpendicular plane containing the $\mathrm{Ag}-\mathrm{Ag}$ axis, namely (6) $a_{g}$, (3) $b_{3 g}$, and 
(6) $a_{g}$

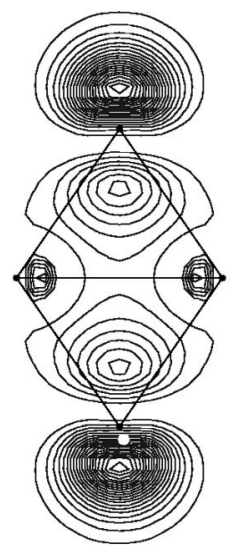

(3) $b_{3 g}$

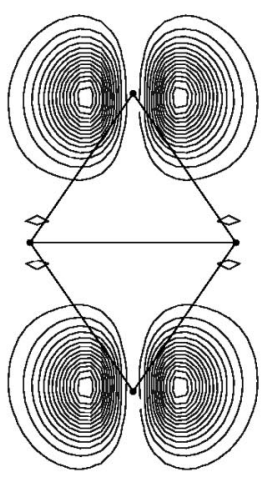

(5) $b_{1 u}$

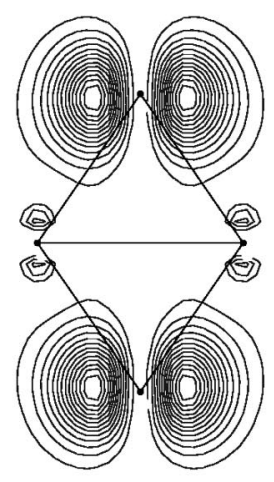

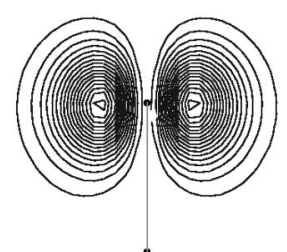

(3) $b_{3 u}$
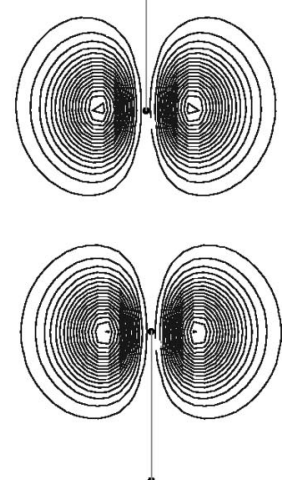

(2) $b_{1 g}$

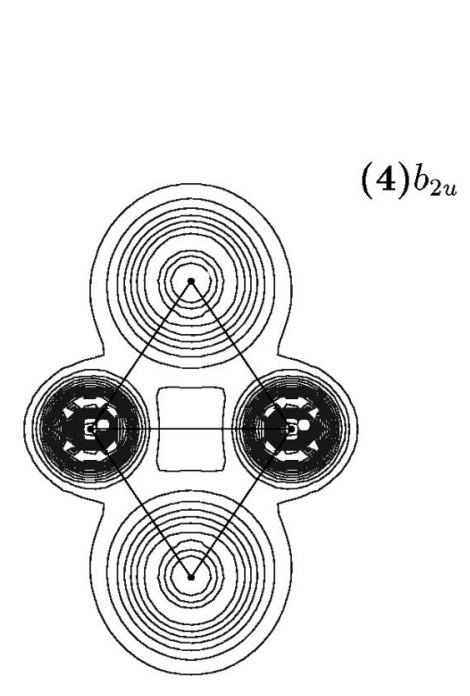

(4) $b_{2 u}$
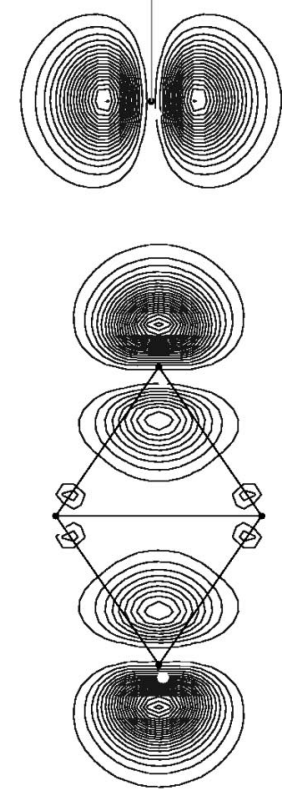

FIG. 4. Density contour plots of representative orbitals and total density contour plot (bottom) of $\mathrm{Ag}_{2} \mathrm{Br}_{2}$.

(5) $b_{1 u}$. As a matter of fact in the inner orbital (6) $a_{g}$ the lobes of the $p$ orbitals of bromine which point inwards restaure some electronic density around and between the two $\mathrm{Ag}^{+}$cations.

The situation is more contrasted in the case of ions. At the CASSCF level, the lowest isomer of $\mathrm{Ag}_{2} \mathrm{Br}_{2}^{+}$has a linear $C_{\infty \mathrm{v}}$ symmetry corresponding to an $\mathrm{Ag}^{+} \mathrm{Br}^{-} \mathrm{Ag}^{+} \mathrm{Br}$ configuration (with respective interatomic distances 4.99, 4.97, and 5. 32 Bohr). The second isomer has a rhombus shape and lies $1.40 \mathrm{eV}$ higher. Interestingly the $\mathrm{Br}-\mathrm{Br}$ distance $\left(5.90 a_{0}\right)$ is

FIG. 5. Density contour plot of the excess electron orbital in $\mathrm{Ag}_{2} \mathrm{Br}_{2}^{-}$. 
smaller than the $\mathrm{Ag}-\mathrm{Ag}$ distance and close to that of $\mathrm{Br}_{2}^{-}\left(5.46 a_{0}\right)$. This is consistent with the fact that the electron is removed from the (4) $b_{2 u}$ orbital (correlated with the $\sigma_{u}$ molecular orbital of $\mathrm{Br}_{2}$ ), yielding an electronic configuration close to $\mathrm{Ag}^{+} \mathrm{Br}_{2}^{-} \mathrm{Ag}^{+}$. However, the situation is strongly changed in the MRPT2 calculation. At the CASSCF geometry, the MRPT2 calculation yields the rhombus 1.69 $\mathrm{eV}$ below the linear structure. The geometry was further optimized at the MRPT2 level with $D_{2 h}$ symmetry constraint. This results into a considerable decrease of the $\mathrm{Ag}-\mathrm{Ag}$ distance which now becomes the shortest diagonal of the rhombus and a $\mathrm{Ag} \widehat{\mathrm{Br}} \mathrm{Ag}$ angle of 80.2 degrees. The $\mathrm{AgBr}$ distances are reduced from $5.34 a_{0}$ to $4.97 a_{0}$. One should however be aware that the rhombus MRTP2 energy change between the rhombus CASSCF optimal geometry and the latter one is only $\Delta E=0.25 \mathrm{eV}$. We have performed DFT type calculations which yield the opposite result with $\Delta E=$ $-0.54 \mathrm{eV}$ (B3LYP functional). ${ }^{49}$

Again in the case of $\mathrm{Ag}_{2} \mathrm{Br}_{2}^{-}$, the linear shape in the CASSCF approximation is lower by $1.62 \mathrm{eV}$ with respect to a rhombus isomer. The linear geometry corresponds to configuration $\mathrm{Br}^{-} \mathrm{Ag}^{+} \mathrm{Br}^{-} \mathrm{Ag}$. The $\mathrm{Ag}^{+} \mathrm{Br}^{-}$interionic distances in this cluster (4.84 and $4.92 a_{0}$ ) are close to that in $\mathrm{AgBr}_{2}^{-}\left(4.89 a_{0}\right)$, whereas the $\mathrm{Br}^{-} \mathrm{Ag}$ distance is $5.66 a_{0}$ to be compared with that of the $\mathrm{AgBr}^{-}$dimer $\left(5.15 a_{0}\right)$. The geometry of the rhombus is close to that of the neutral tetramer and corresponds to the addition of an electron in orbital (7) $a_{g}$, essentially extending away from the cluster on each side of the silver atoms (Fig. 5). When MRPT2 calculations are considered for the same CASSCF structures, the order is reversed and the $D_{2 h}$ rhombus appears as strongly stabilized lying now $2.64 \mathrm{eV}$ below the linear chain. MRPT2 further optimization slightly shortens the $\mathrm{AgBr}$ distance from 5.26 to $5.08 a_{0}$ and the $\mathrm{Ag} \widehat{\mathrm{BrAg}}$ angle from 74.9 to 64.3 degrees.

Up to now, we have essentially discussed qualitatively charge transfer and delocalization of the electronic cloud involving components on the $5 s$ orbitals of silver and $4 p$ orbitals of bromine. For atoms with significant overlaps of atomic orbitals at equilibrium and when extended basis sets are used, one should be cautious when examining the Mulliken populations. Nevertheless as an indicative feature, we discuss the populations of the species without excess electrons at the CASSCF approximation. In all cases, the Mulliken population indicates only a partial charge transfer. In $\mathrm{AgBr}$, the charge on $\mathrm{Ag}$ remains 0.50. In $\mathrm{Ag}_{2} \mathrm{Br}^{+}$, the charge on each silver atom remains 0.64 , that on bromine is -0.28 . We have already mentioned that orbitals (7) $b_{2}$ and (8) $a_{1}$ (Fig. 3) extend somewhat towards the silver atoms, but still keep the aspect of essentially $\mathrm{Br}^{-}$center $p$ orbitals. The Mulliken criterion thus seems to understate charge transfer. Due to the large $\mathrm{Ag}-\mathrm{Ag}$ distance $(d=8.0 \mathrm{Bohr})$, an $\mathrm{Ag}_{2}^{+} \mathrm{Br}$ type description does not actually seem to be adequate, despite the Mulliken population results. In $\mathrm{AgBr}_{2}^{-}$, the charge on silver is 0.44 and -0.72 on each bromine atom. In the rhombus isomer of $\mathrm{Ag}_{2} \mathrm{Br}_{2}$, the charge transfer is equal to 0.54 on each $\mathrm{AgBr}$ bond. According to the Mulliken criterion, the bonding cannot be analyzed as totally ionic. Besides of a possible exageration of this departure from ionic character in the Mulliken analysis, such an incomplete charge transfer is to be attributed to non vanishing overlaps. Starting from the separated ionized fragments this would appear as resulting from non orthogonality in a nonorthogonal valence-bond scheme, or alternatively from orthogonalization of the atomic orbitals in a orthogonal valence-bond scheme. This aspect is closely connected to the limit of the Mulliken analysis. Such a valence-bond analysis would be interesting in further work. It may be more pertinent to analyze the Mulliken population in the $4 d$ orbitals of silver, since the latter are more localized. Actually, for most clusters, the variation of the population of the CASSCF $d$ orbitals with respect to the isolated atom situation (two electrons per $d$ orbital) is extremely weak, usually less than one percent, with two exceptions. The first one is $\mathrm{AgBr}_{2}^{-}$in which orbital $d_{\sigma}$ has 1.96 electrons, and the second case is $\mathrm{Ag}_{2} \mathrm{Br}_{2}^{+}$in which the population of orbital $d$ contributing to the $b_{2 u}$ representation is 1.95 .

We now discuss the ionization potentials and electron affinities of clusters. The CASSCF ionization potentials and electron-affinities calculated for trimers are systematically smaller than the MRPT2 values (Tables III and IV) because of lack of correlation. The MRPT2 adiabatic ionization potentials of $\mathrm{Ag}_{2} \mathrm{Br}$ and $\mathrm{AgBr}_{2}$ are, respectively, 5.88 and 8.02 $\mathrm{eV}$, illustrating the reorganization of the geometry of ions versus neutrals. Still more striking is the different behavior of the electron affinities between $\mathrm{Ag}_{2} \mathrm{Br}$ and $\mathrm{AgBr}_{2}$. For the former, the vertical and adiabatic electron affinities, are almost identical (1.77 and $1.63 \mathrm{eV}$, respectively). For the latter, they are significantly different, respectively, $4.85 \mathrm{eV}$ and $2.23 \mathrm{eV}$. This illustrates further the geometrical similarity between $\mathrm{Ag}_{2} \mathrm{Br}$ and $\mathrm{Ag}_{2} \mathrm{Br}^{-}$, the added electron completing the last occupied $\mathrm{Ag}_{2}$ orbital, and oppositely the strong reorganization occurring between $\mathrm{AgBr}_{2}$ and $\mathrm{AgBr}_{2}^{-}$(change from almost equilateral to linear geometry). In the case of tetramers the vertical and adiabatic ionization potentials are 8.78 and $9.15 \mathrm{eV}$, respectively, whereas the vertical and adiabatical electron affinities are almost identical $(0.79 \mathrm{eV})$ due to the very similar geometries of $\mathrm{Ag}_{2} \mathrm{Br}_{2}$ and $\mathrm{Ag}_{2} \mathrm{Br}_{2}^{-}$.

\section{DISCUSSION}

The above results have shown that species such as $\mathrm{AgBr}_{2}^{-}, \mathrm{Ag}_{2} \mathrm{Br}^{+}$, and $\mathrm{Ag}_{2} \mathrm{Br}_{2}$ can be characterized as ionic clusters with a stability dominated by charge transfer, despite of a non-negligeable overlap. However, if one considers the electrostatic interactions as resulting from purely localized and equivalent positive $\left(\mathrm{Ag}^{+}\right)$and negative $\left(\mathrm{Br}^{-}\right)$point charges, one would expect $\mathrm{Ag}_{2} \mathrm{Br}^{+}$to be linear and $\mathrm{Ag}_{2} \mathrm{Br}_{2}$ to be a square. The actual clusters are significantly distorted with respect to those ideal shapes.

In addition to the non identical $\mathrm{Ag}^{+}-\mathrm{Ag}^{+}$and $\mathrm{Br}^{-}-\mathrm{Br}^{-}$ repulsion potentials which certainly play a role, an important contribution to the distorsion is due to the polarization contribution which exhibits a trend to maximize the electrostatic field on the atoms with larger polarization, namely negatively charged bromine. Thus in $\mathrm{Ag}_{2} \mathrm{Br}^{+}$, the cluster distorts from linearity in order to depart from an otherwise vanishing electric field on the medium bromine atom. Similarly in 
TABLE VII. Fragmentation energies (eV) for dissociation channels of neutral and singly charged (positively and negatively) clusters.

\begin{tabular}{|c|c|c|c|c|c|c|}
\hline & \multicolumn{2}{|c|}{ Neutral } & \multicolumn{2}{|c|}{ Anion } & \multicolumn{2}{|l|}{ Cation } \\
\hline \multicolumn{7}{|l|}{$\mathrm{Ag}_{2} \mathrm{Br}$} \\
\hline & $\mathrm{AgBr}+\mathrm{Ag}$ & 0.94 & $\mathrm{Ag}_{2}+\mathrm{Br}^{-}$ & 0.25 & $\mathrm{AgBr}+\mathrm{Ag}^{+}$ & 2.22 \\
\hline & $\mathrm{Ag}_{2}+\mathrm{Br}$ & 1.50 & $\mathrm{AgBr}^{-}+\mathrm{Ag}$ & 1.20 & $\mathrm{Ag}_{2}^{+}+\mathrm{Br}$ & 3.20 \\
\hline & $2 \mathrm{Ag}+\mathrm{Br}$ & 3.59 & $\mathrm{AgBr}+\mathrm{Ag}^{-}$ & 1.34 & $\mathrm{AgBr}^{+}+\mathrm{Ag}$ & 3.90 \\
\hline & & & $2 \mathrm{Ag}+\mathrm{Br}^{-}$ & 2.33 & $\mathrm{Ag}_{2}+\mathrm{Br}^{+}$ & 6.81 \\
\hline & & & $\mathrm{Ag}_{2}^{-}+\mathrm{Br}$ & 2.43 & & \\
\hline \multicolumn{7}{|l|}{$\mathrm{AgBr}_{2}$} \\
\hline & $\mathrm{AgBr}+\mathrm{Br}$ & 0.99 & $\mathrm{AgBr}+\mathrm{Br}^{-}$ & 2.82 & $\mathrm{Ag}^{+}+\mathrm{Br}_{2}$ & 1.08 \\
\hline & $\mathrm{Ag}+\mathrm{Br}_{2}$ & 1.93 & $\mathrm{Ag}+\mathrm{Br}_{2}^{-}$ & 4.23 & $\mathrm{AgBr}^{+}+\mathrm{Br}$ & 1.81 \\
\hline & $\mathrm{Ag}+2 \mathrm{Br}$ & 3.63 & $\mathrm{AgBr}^{-}+\mathrm{Br}$ & 4.33 & $\mathrm{Ag}^{+}+2 \mathrm{Br}$ & 2.78 \\
\hline & & & $\mathrm{Ag}^{-}+\mathrm{Br}_{2}$ & 5.41 & $\mathrm{Ag}+\mathrm{Br}_{2}^{+}$ & 4.11 \\
\hline & & & & & $\mathrm{AgBr}+\mathrm{Br}^{+}$ & 4.16 \\
\hline \multicolumn{7}{|l|}{$\mathrm{Ag}_{2} \mathrm{Br}_{2}$} \\
\hline & $2 \mathrm{AgBr}$ & 2.00 & $\mathrm{AgBr}_{2}^{-}+\mathrm{Ag}$ & -0.40 & $\mathrm{Ag}_{2} \mathrm{Br}^{+}+\mathrm{Br}$ & 0.80 \\
\hline & $\mathrm{Ag}_{2}+\mathrm{Br}_{2}$ & 3.51 & $\mathrm{AgBr}+\mathrm{AgBr}^{-}$ & 1.28 & $\mathrm{AgBr}_{2}+\mathrm{Ag}^{+}$ & 2.04 \\
\hline & $\mathrm{AgBr}_{2}+\mathrm{Ag}$ & 3.66 & $\mathrm{Ag}_{2} \mathrm{Br}+\mathrm{Br}^{-}$ & 1.47 & $\mathrm{AgBr}+\mathrm{AgBr}^{+}$ & 2.05 \\
\hline & $\mathrm{Ag}_{2} \mathrm{Br}+\mathrm{Br}$ & 3.70 & $\mathrm{Ag}_{2} \mathrm{Br}^{-}+\mathrm{Br}$ & 2.73 & $\mathrm{AgBr}_{2}^{+}+\mathrm{Ag}$ & 2.89 \\
\hline & & & $\mathrm{AgBr}_{2}+\mathrm{Ag}^{-}$ & 3.08 & $\mathrm{Ag}_{2} \mathrm{Br}+\mathrm{Br}^{+}$ & 6.11 \\
\hline
\end{tabular}

$\mathrm{Ag}_{2} \mathrm{Br}_{2}$, the shortening of the $\mathrm{Ag}-\mathrm{Ag}$ distance with respect to the $\mathrm{Br}-\mathrm{Br}$ one enhances the field on the two bromine atoms. In order to check this interpretation, and despite the conclusions of the Mulliken analysis, we have implemented an electrostatic model involving repulsion forces, Coulomb interactions between point charges located on $\mathrm{Ag}^{+}$and $\mathrm{Br}^{-}$ and damped polarization contributions. The parameters are taken from $a b$ initio potential energy curves on the $\mathrm{AgBr}$, $\mathrm{Ag}^{+} \mathrm{Ag}^{+}$, and $\mathrm{Br}^{-} \mathrm{Br}^{-}$dimers. One problem arises with polarization contributions due to the magnitude of the polarizability of $\mathrm{Br}^{-}\left(\alpha\left(\mathrm{Ag}^{+}\right)=8.273 \mathrm{bohr}^{3},{ }^{16} \quad \alpha\left(\mathrm{Br}^{-}\right)\right.$ $=37.16 \mathrm{bohr}^{350}$ ) and the fact that neither $\mathrm{Ag}^{+}$nor $\mathrm{Br}^{-}$ should actually be considered as actual point charges. Thus there is a difficulty at distances smaller than 5.5 Bohr due to a possible divergency of the polarization term with power $R^{-4}$. We have circumvented this problem by damping the $R^{-2}$ electric field with a factor of the type $\left(1-\exp \left(-\delta r^{2}\right)\right)$, in analogy with the suggestion of Flad et al. ${ }^{16}$ The geometries obtained with this simple model are consistent with those of the $a b$ initio calculations, namely a linear $D_{\infty h}$ geometry for $\mathrm{AgBr}_{2}^{-}(d=4.9$ bohr $)$, a bent $C_{2 \mathrm{v}}$ geometry for $\mathrm{Ag}_{2} \mathrm{Br}^{+}(d=4.45$ bohr, $\theta=110$ degrees $)$, and a rhombus geometry for $\mathrm{Ag}_{2} \mathrm{Br}_{2}$ (with $d(\mathrm{AgBr})=4.9 \mathrm{bohr}$ and $\mathrm{Ag} \widehat{\mathrm{Br}} \mathrm{Ag}$ $=70$ degrees). One should mention that such distorsions due to differences in the polarizabilities of the constituent atoms have already been evidenced on other ionic clusters and on surfaces, in particular oxides. ${ }^{23-25}$

It is also interesting to comment the dissociation energies of the small clusters which are listed in Table VII with respect to the various accessible channels. One can first notice that the most stable clusters are the simply ionic $\mathrm{Ag}_{2} \mathrm{Br}^{+}$ and $\mathrm{AgBr}_{2}^{-}$species just discussed above, with dissociation energies towards the lowest energy channels larger than 2 $\mathrm{eV}, \mathrm{AgBr}_{2}^{-}$being the most stable of all $(2.82 \mathrm{eV})$. The other clusters have dissociation energies of the order of $1 \mathrm{eV}$ with two exceptions. One is the $\mathrm{Ag}_{2} \mathrm{Br}^{-}$anion which is only stable by $0.25 \mathrm{eV}$. The second exception is more significant; indeed as already mentioned the $\mathrm{Ag}_{2} \mathrm{Br}_{2}^{-}$anion is stable with respect to the $\mathrm{Ag}_{2} \mathrm{Br}_{2}$ cluster (positive electron affinity) but is found here only metastable with respect to the dissociation into $\mathrm{AgBr}_{2}^{-}+\mathrm{Ag}$, feature which is clearly related to the large stability of the trimer. Another remark concerns the fragmentation channels themselves; it is seen that in some cases the lowest energy products involve an ionized atom and a neutral dimer and that the charge is obviously not always localized on the largest fragment. This stems from the fact that the IP's of $\mathrm{Br}_{2}$ and $\mathrm{AgBr}$ are larger that of $\mathrm{Ag}$ and that the EA of $\mathrm{Ag}_{2}$ and $\mathrm{AgBr}$ are smaller that of $\mathrm{Br}$.

\section{CONCLUSION}

We have presented ab initio determinations of the structural and electronic properties of small silver halide clusters. Even for some dimers $\mathrm{AgBr}^{( \pm)}$, the present results are the first theoretically available. The stability of the clusters can mainly be associated with the prevalence of electrostatic interactions and their ionic character, although the Mulliken population (not necessarily significant) seems to indicate only partial charge transfer. The most stable species are $\mathrm{AgBr}_{2}^{-}, \mathrm{Ag}_{2} \mathrm{Br}^{+}$, and $\mathrm{Ag}_{2} \mathrm{Br}_{2}$ which would have no excess electrons with respect to total charge transfer. The orbitals of excess electrons with respect to the saturated charge transfer configuration turn out to be rather delocalised. This delocalisation is correlated with the similarities of the bond length of the constitutive dimers together with the diffuse character of the $5 s$ orbital of silver atoms by which the excess electron is spanned. The population analysis shows that the $d$ shell undergoes only a marginal participation in the bonding, except perhaps for the $\mathrm{AgBr}_{2}^{-}$and $\mathrm{Ag}_{2} \mathrm{Br}_{2}^{+}$. The unequivalent polarizabilities on silver cation and bromine anion and the particularly large polarizability of bromine anion induce an important influence of the polarization contributions on the equilibrium geometries of clusters. We have determined the stabilities, the electron affinities and the ionization potentials 
of those small clusters and those theoretical data should allow to help for the interpretation of current experimental investigations which are underway.

${ }^{1}$ E. S. Rittner, J. Chem. Phys. 19, 1030 (1951).

${ }^{2}$ D. O. Welch, O. W. Lazareth, and G. J. Dienes, J. Chem. Phys. 64, 835 (1976); D. O. Welch, O. W. Lazareth, G. J. Dienes, and R. D. Hatcher ibid. 68, 2159 (1978).

${ }^{3}$ J. Diefenbach and T. P. Martin, J. Chem. Phys. 83, 4585 (1985).

${ }^{4}$ N. G. Phillips, C. W. S. Conover, and L. A. Bloomfield, J. Chem. Phys. 94, 4980 (1991).

${ }^{5}$ R. N. Barnett, H.-P. Cheng, H. Hakkinen, and U. Landman, J. Phys. Chem. 99, 7731 (1995).

${ }^{6}$ V. Bonačić-Koutecký, J. Pittner, and J. Koutecky, Chem. Phys. 210, 313 (1996).

${ }^{7}$ U. Landman, D. Scharf, and J. Jortner, Phys. Rev. Lett. 54, 1860 (1985).

${ }^{8}$ J. Rajagopal, R. N. Barnett, A. Nitzan, U. Landman, E. C. Honea, P. Labastie, M. L. Homer, and R. L. Whetten, Phys. Rev. Lett. 64, 2933 (1990).

${ }^{9}$ G. Durand, J. Giraud-Girard, D. Maynau, F. Spiegelmann, and F. Calvo, J. Chem. Phys. 110, 7871 (1999).

${ }^{10}$ G. Durand, F. Spiegelmann, Ph. Poncharal, P. Labastie, J. M. L'Hermite, and M. Sence, J. Chem. Phys. 110, 7884 (1999).

${ }^{11}$ M. Mostafavi, J. L. Marignier, J. Amblard, and J. Belloni, Z. Phys. D 12, 31 (1989).

${ }^{12}$ P. Fayet, F. Granzer, G. Hegenbart, E. Moisar, B. Pischel, and L. Woste, Z. Phys. D 3, 299 (1986).

${ }^{13}$ M. Bucher, Phys. Rev. B 30, 947 (1984).

${ }^{14}$ C.-H. Kiang and W. A. Goddard, J. Phys. Chem. 99, 14334 (1995).

${ }^{15}$ R. K. Hailstone and D. E. Erdtmann, J. Appl. Phys. 76, 4184 (1994).

${ }^{16}$ J. Flad, H. Stoll, and H. Preuß, Z. Phys. D 6, 193 (1987); 6, 287 (1987).

${ }^{17}$ J. Flad, H. Stoll, A. Nicklass, and H. Preuß, Z. Phys. D 15, 79 (1990).

${ }^{18}$ R. C. Baetzold, J. Phys. Chem. 101, 8180 (1997).

${ }^{19}$ G. Pacchioni, P. S. Bagus, and M. R. Philpott, Z. Phys. D 12, 543 (1989).

${ }^{20}$ R. Santamaria, I. G. Kaplan, and O. Novaro, Chem. Phys. Lett. 218, 395 (1994).

${ }^{21}$ V. Bonačić-Koutecký, J. Pittner, M. Boiron, and P. Fantucci, J. Chem. Phys. 110, 3876 (1999).

${ }^{22}$ V. Bonačić-Koutecký, M. Boiron, J. Pittner, P. Fantucci, and J. Koutecký, Europ. Phys. J. D, ISSPIC 9 Proceeding (in press).

${ }^{23}$ M. J. Malliavin, Ph.D. Thesis, Ecole Polytechnique, Palaiseau France, 1999; M. J. Malliavin and C. Coudray, J. Chem. Phys. 106, 2323 (1997).

${ }^{24}$ F. Finocchi and C. Noguera, Phys. Rev. B 53, 4989 (1996).
${ }^{25}$ F. Finocchi and C. Noguera, Phys. Rev. B 57, 14646 (1998).

${ }^{26}$ D. Andrae, U. Häußermann, M. Dolg, H. Stoll, and H. Preuß, Theor. Chim. Acta 77, 123 (1990).

${ }^{27}$ A. Bergner, M. Dolg, W. Kuechle, H. Stoll, and H. Preuß, Mol. Phys. 80, 1431 (1993).

${ }^{28}$ A. Ramirez-Solis, J. P. Daudey, O. Novaro, and M. E. Ruiz, Z. Phys. D 15, 71 (1990).

${ }^{29}$ MOLCAS Version 4. K. Andersson, M. R. A. Blomberg, M. P. Fülscher, G. Karlström, R. Lindh, P. A. Malmqvist, P. Neogrády, J. Olsen, B. O. Roos, A. J. Sadlej, M. Schütz, L. Seijo, L. Serrano-Andrés, P. E. M. Siegbahn, and P. O. Widmark, Lund University, Sweden, 1997.

${ }^{30}$ S. Evangelisti, J. P. Daudey, and J. P. Malrieu, Chem. Phys. 75, 91 (1983).

${ }^{31}$ C. Moller and M. S. Plesset, Phys. Rev. 46, 618 (1934).

${ }^{32}$ H. Hotop and W. C. Lineberger, J. Phys. Chem. Ref. Data 14, 731 (1985).

${ }^{33}$ E. R. Cohen and B. N. Taylor, J. Phys. Chem. Ref. Data 17, 1795 (1988).

${ }^{34}$ C. Blondel, P. Cacciani, C. Delsart, and R. Trainlam, Phys. Rev. A 40, 3698 (1989)

${ }^{35}$ V. Beutel, H.-G. Krämer, G. L. Bhale, M. Kuhn, K. Weyers, and W. Demtröder, J. Chem. Phys. 98, 2699 (1993).

${ }^{36}$ K. P. Huber and G. Herzberg, Molecular Spectra and Molecular Structure, Vol. 4, Constants of Diatomic Molecules (Van Nostrand Reinhold, New York, 1979)

${ }^{37}$ K. P. R. Nair and J. Hoeft, Phys. Rev. A 35, 668 (1987).

${ }^{38}$ D. Andrae, U. Häußermann, M. Dolg, H. Stoll, and H. Preuß, Theor. Chim. Acta 78, 247 (1991).

${ }^{39}$ C. W. Bauschlicher, S. R. Langhoff, and H. Partridge, J. Chem. Phys. 91, 2412 (1989).

${ }^{40}$ K. Balasubramanian and Ping Yi Feng, Chem. Phys. Lett. 159, 452 (1989).

${ }^{41}$ R. L. Martin, J. Chem. Phys. 86, 5027 (1987).

${ }^{42}$ S. P. Walch, C. W. Bauschlicher, and S. R. Langhoff, J. Chem. Phys. 85, 5900 (1986).

${ }^{43}$ M. D. Morse, Chem. Rev. 86, 1049 (1986).

${ }^{44}$ A. B. Sannigrahi and S. D. Peyerimhoff, Chem. Phys. Lett. 148, 197 (1988).

${ }^{45}$ K. Balasubramanian, Chem. Phys. 119, 41 (1988).

${ }^{46}$ J. Berkowitz, C. H. Batson, and G. L. Goodman, J. Chem. Phys. 11, 5829 (1980)

${ }^{47}$ P. S. Drzaic, J. Marks, and J. I. Brauman, Gas Phase Ion Chemistry, edited by M. T. Bowers (Academic, Orlando, 1984), Vol. 3.

${ }^{48}$ J. Ho, K. M. Ervin, and C. Linberger, J. Chem. Phys. 93, 6987 (1990).

${ }^{49}$ F. Rabilloud and F. Spiegelmann (unpublished).

${ }^{50}$ P. C. Schmidt, A. Weiss, and T. P. Das, Phys. Rev. B 19, 5525 (1979). 